\title{
A Retrospective Study from Turkey: Assessment of first Application Findings of Children with Type 1 Diabetes Diagnosis in Ordu
}

\author{
Emine Yurdakul Ertürk ${ }^{1}$, Arzu Şahin ${ }^{2}$, Eda Dokumacioglu ${ }^{3}$, Soner Çankaya ${ }^{4}$ \\ ${ }^{1}$ Ordu University, Faculty of Medicine, Pediatric Health and Diseases Department, Ordu, Turkey \\ ${ }^{2}$ Ordu University, Faculty of Medicine, Physiology Department, Ordu, Turkey \\ ${ }^{3}$ Artvin Çoruh University, Faculty of Health Sciences, Nutrition and Dietetics Department, Artvin, Turkey \\ ${ }^{4}$ Ordu University, Faculty of Medicine, Biostatistics Department, Ordu, Turkey
}

Received: 07 June 2017, Accepted: 07 August 2017, Published online 28 August 2017

(C) Ordu University Institute of Health Sciences, Turkey, 2017

\begin{abstract}
Objective: Type 1 diabetes mellitus (T1DM) is one of the most common chronic endocrine diseases encountered in childhood and adolescent periods. This study aims to assess the biochemical and epidemiological characteristics of children monitored for T1DM diagnosis in Ordu.

Methods: This study investigated some biochemical and epidemiological characteristics of a total of 40 (20 boys, 20 girls) children ranging in age from 3 to 16 years with first diagnosis and follow-up at Ordu University Faculty of Medicine Education and Research Hospital Pediatric Health and Diseases Department from 2012 to 2016. Children participating in the study were divided into 2 groups as aged 3-9 years and 1016 years. Group I included children aged from 3-9 years, while Group II included children aged from 10-16 years. The distribution according to gender and peak age for first diagnosis were examined. The study retrospectively investigated the fasting plasma glucose, HbA1C, AST, ALT, Na, K, Cl, triglyceride, cholesterol, BUN, creatinine, white cells, hemoglobin, urine $\mathrm{pH}$, urine density, urine glucose, blood $\mathrm{pH}$ and $\mathrm{HCO} 3$ values of pediatric patients applying for the first time and receiving diagnosis of T1DM.

Results: Our patients included 20 girls (50\%) and 20 boys (50\%). The lowest diabetes age was 3 years with highest 16 years. According to age distribution of patients, the peak age of disease was 11 years $(22.5 \%)$ and there were 17 patients $(42.5 \%)$ in the 3-9 age group and $23(57.5 \%)$ in the 10-16 age group. When biochemical parameters are compared in terms of gender, the TG value in girls $(104.9 \pm 42.9)$ was found to be statistically significantly high compared to the TG value for boys $(68.3 \pm 17.2)(p<0.05)$. However, there was no other statistically significant difference identified for any other biochemical parameter in terms of gender.

Conclusion: It is accepted that the incidence of T1DM is increasing globally and the age of diagnosis is falling. Early diagnosis and developing effective treatment of T1DM patients is very important in terms of preventing possible complications.
\end{abstract}

Key words: Ordu, type 1 diabetes, children

Address for correspondence/reprints:

Arzu Şahin

Telephone number: +90 (506) 6001497

E-mail: sahin-97@yahoo.com 


\section{Introduction}

T1DM is a chronic immune-mediated disease characterized by loss of insulin-producing $\beta$ cells in the pancreatic langerhans islets and is the most common endocrinological disease in the childhood period (Onkamo et al. 1990; Aydin et al. 2016). In many countries in the last 20 years, there is a clear increase observed in the incidence of T1DM in children below the age of 15 years, with the number of newly-diagnosed patients increasing by $2-5 \%$ each year. Though the reasons for this increase are not very clear, many environmental factors are blamed.

Studies have reported that in addition to the increase in patient numbers, numbers applying with milder symptoms have increased, there is a reduction in severe ketoacidosis coma and the number of diabetic children under the age of 5 has increased (Bideci et al. 2006; Hamman et al. 2014).

For diagnosis of diabetes mellitus (DM) in a symptomatic case, fasting plasma glucose above 126 $\mathrm{mg} / \mathrm{dl}$ or blood glucose at any time above $200 \mathrm{mg} / \mathrm{dl}$ are sufficient criteria for diagnosis (Alberti and Zimmet 1998). T1DM is a chronic progressive disease with high morbidity and mortality (Cruickshanks et al. 1985). The incidence of T1DM varies with age, race, geographical region and season.

T1DM is essentially a childhood period disease. It may begin in any age group in the childhood and adolescent periods, with two peaks of highest incidence in the "5-7 age" group and "pubertal period" (Onkamo et al. 1990; EURODIAB ACE Study Group 2000). This study was planned with the aim of assessing the biochemical and epidemiological characteristics of children monitored for T1DM diagnosis in Ordu.

\section{Material and Method}

This study investigated some biochemical and epidemiological characteristics of a total of 40 (20 boys, 20 girls) children ranging in age from 3 to 16 years with first diagnosis and follow-up at Ordu University Faculty of Medicine Education and Research Hospital Pediatric Health and Diseases Department from 2012 to 2016. Those with missing file information and who began treatment at another center before being sent to our hospital were excluded from the study. To participate in the research families of patients completed an informed consent form after necessary information was given.
The files of patients were investigated and the clinical and laboratory findings at time of first diagnosis were retrospectively recorded. The patients' files were investigated for clinical symptoms and findings at first application, gender, date of T1DM diagnosis (year), calendar age at diagnosis and blood biochemical values.

Children participating in the study were divided into 2 groups as aged 3-9 years and 10-16 years. Group I included children aged from 3-9 years while Group II included children aged from 10-16 years. The distribution according to gender and peak age for first diagnosis were examined. The study retrospectively investigated the fasting plasma glucose, HbA1C, AST, ALT, Na, K, Cl, triglyceride, cholesterol, BUN, creatinine, white cells, hemoglobin, urine $\mathrm{pH}$, urine density, urine glucose, blood $\mathrm{pH}$ and $\mathrm{HCO} 3$ values of pediatric patients applying for the first time and receiving diagnosis of T1DM.

\section{Statistical Analysis}

All the data analysis was performed using SPSS 11.0 for Windows software (SPSS Inc., NY, USA). The values between the groups (s intervals or gender) were analyzed by using Student t-test according to the results of Levene test and Shapiro Wilk test for equality of variances and the normality assumption, respectively $(\mathrm{P}>0.05)$. Data are presented as sample size (n), mean with standard deviation. Significance was evaluated at $\mathrm{P}<0.05$ for all tests.

\section{Results}

Of 40 patients included in the study, there were 20 girls $(50 \%)$ and 20 boys (50\%). The lowest diabetes age was 3 years with highest 16 years. According to age distribution of patients, the peak age of disease was 11 years $(22.5 \%)$ and there were 17 patients $(42.5 \%)$ in the 3-9 age group and 23 $(57.5 \%)$ in the 10-16 age group. On first application to hospital 10 children (25\%) had ketoacidosis and 3 $(7.5 \%)$ were in a coma. Of patients with ketoacidosis, 4 were in the 3-9 age group and 6 were in the 10-16 age group. All of the patients who were in a coma were in the 10-16 age group. The biochemical results of the study groups are presented in Table 1 . When the study groups are assessed according to age group, there was no statistically significant difference observed in fasting plasma glucose, HbA1C, ALT, triglyceride, $\mathrm{Na}, \mathrm{K}, \mathrm{Cl}$, total cholesterol, BUN, creatinine, white. 
Tablo 1. Laboratory features for T1DM by age group

\begin{tabular}{lccc}
\hline $\begin{array}{l}\text { Laboratory } \\
\text { features }\end{array}$ & $\begin{array}{c}\text { Group 2 } \\
(\mathbf{1 0 - 1 6} \text { age })\end{array}$ & $\begin{array}{c}\text { Group 2 } \\
(\mathbf{1 0 - 1 6} \text { age })\end{array}$ & P-value \\
\hline Glucose & $289.10 \pm 155.60$ & $314.10 \pm 200.30$ & 0.673 \\
HbA $A_{l c}$ & $7.99 \pm 1.91$ & $8.81 \pm 2.93$ & 0.323 \\
$A S T$ & $24.02 \pm 6.57$ & $18.8 \pm 5.43^{*}$ & 0.007 \\
$A L T$ & $16.10 \pm 5.97$ & $14.4 \pm 4.86$ & 0.337 \\
$T C$ & $87.28 \pm 12.08$ & $90.20 \pm 10.21$ & 0.327 \\
$T G$ & $89.00 \pm 32.59$ & $96.60 \pm 44.63$ & 0.765 \\
$B U N$ & $18.90 \pm 10.99$ & $19.40 \pm 11.84$ & 0.907 \\
Creatinine & $0.65 \pm 0.20$ & $0.74 \pm 0.29$ & 0.274 \\
Na & $136.00 \pm 3.20$ & $138.20 \pm 4.70$ & 0.105 \\
$K$ & $4.18 \pm 0.46$ & $4.19 \pm 0.49$ & 0.946 \\
Hb & $12.9 \pm 1.68$ & $14.1 \pm 1.18 *$ & 0.028 \\
Urine glucose & $3.08 \pm 1.50$ & $2.37 \pm 1.80$ & 0.252 \\
Urine pH & $5.96 \pm 0.84$ & $5.92 \pm 0.93$ & 0.911 \\
Urine density & $1021.10 \pm 11.20$ & $1021.10 \pm 10.40$ & 0.994 \\
Blood pH & $7.22 \pm 0.17$ & $7.29 \pm 0.10$ & 0.345 \\
HCO & $14.10 \pm 5.94$ & $19.20 \pm 7.93$ & 0.162
\end{tabular}

Data were given as mean \pm SD.

AST: Aspartate aminotransferase, ALT: Alanine aminotransferase, TC: total cholesterol, TG: triglyceride; BUN: blood urea nitrogene, $\mathrm{HCO}_{3}$ : bicarbonate, $\mathrm{Hb}$ : hemoglobin, $\mathrm{Na}$ : sodium, $\mathrm{K}$ :potassium

* Significantly different when compared with control group, $(\mathrm{p}<0.05)$.

Tablo 2. Laboratory features for T1DM by gender group.

\begin{tabular}{lccc}
\hline $\begin{array}{l}\text { Laboratory } \\
\text { features }\end{array}$ & $\begin{array}{c}\text { Group 1 } \\
\text { (Female) }\end{array}$ & $\begin{array}{c}\text { Group 2 } \\
\text { (Male) }\end{array}$ & P-value \\
\hline Glucose $^{\text {(MbA }}$ & $325.10 \pm 171.90$ & $282.20 \pm 189.80$ & 0.613 \\
$\mathrm{HbA}_{1 \mathrm{c}}$ & $8.79 \pm 2.28$ & $8.14 \pm 2.82$ & 0.428 \\
$\mathrm{AST}$ & $20.04 \pm 7.25$ & $21.90 \pm 5.90$ & 0.485 \\
$\mathrm{ALT}$ & $15.20 \pm 6.13$ & $15.10 \pm 4.6$ & 0.954 \\
$\mathrm{TC}$ & $97.28 \pm 22.08$ & $92.16 \pm 10.2$ & 0.603 \\
$\mathrm{TG}$ & $104.90 \pm 42.90$ & $68.30 \pm 18.20^{*}$ & 0.042 \\
$\mathrm{BUN}$ & $18.80 \pm 12.60$ & $19.60 \pm 10.30$ & 0.824 \\
$\mathrm{Creatinine}$ & $0.73 \pm 0.30$ & $0.68 \pm 0.20$ & 0.559 \\
$\mathrm{Na}$ & $137.50 \pm 4.50$ & $137.10 \pm 4.85$ & 0.767 \\
$\mathrm{~K}$ & $4.20 \pm 0.53$ & $4.17 \pm 0.43$ & 0.819 \\
$\mathrm{Hb}$ & $13.20 \pm 1.78$ & $13.99 \pm 1.12$ & 0.136 \\
Urine glucose & $2.59 \pm 1.84$ & $2.73 \pm 1.58$ & 0.814 \\
Urine pH & $5.66 \pm 0.69$ & $6.23 \pm 0.90$ & 0.068 \\
Urine density & $1020.50 \pm 8.60$ & $1021.80 \pm 12.70$ & 0.728 \\
$\mathrm{Blood} \mathrm{pH}$ & $7.28 \pm 0.08$ & $7.20 \pm 0.21$ & 0.290 \\
$\mathrm{HCO}_{3}$ & $11.10 \pm 6.67$ & $14.60 \pm 7.65$ & 0.512 \\
\hline
\end{tabular}

Data were given as mean \pm SD.

AST: Aspartate aminotransferase, ALT: Alanine aminotransferase, TC: total cholesterol, TG: triglyceride; BUN: blood urea nitrogene, $\mathrm{HCO}_{3}$ : bicarbonate, $\mathrm{Hb}$ : hemoglobin, $\mathrm{Na}$ : sodium, $\mathrm{K}$ :potassium

${ }^{*}$ Significantly different when compared with control group, $(\mathrm{p}<0.05)$. 
cells, hemoglobin, urine $\mathrm{pH}$, urine density, urine glucose, blood $\mathrm{pH}$ and $\mathrm{HCO} 3$ levels ( $\mathrm{p}>0.05$ ) but; the hemoglobin value in group $2\left(14.1 \pm 1.18^{*}\right)$ was found to be statistically significantly high compared to hemoglobin value for the group $1(12.9 \pm 1.68)$ $(\mathrm{p}<0.05)$ and AST value in group $1\left(24.02 \pm 6.57^{*}\right)$ $(\mathrm{p}<0.05)$ was found to be statistically significantly high compared to AST value for the group $2(18.8 \pm$ 5.43).

When biochemical parameters are compared in terms of gender in Table 2., the triglyceride value in girls $(104.9 \pm 42.9)$ was found to be statistically significantly high compared to the TG value for boys $(68.3 \pm 17.2)(p<0.05)$. However, there was no other statistically significant difference identified for fasting plasma glucose, $\mathrm{Hb}, \mathrm{HbA1C}$, ALT, AST, Na, $\mathrm{K}, \mathrm{Cl}, \mathrm{TC}, \mathrm{BUN}$, creatinine, white cells, hemoglobin, urine $\mathrm{pH}$, urine density, urine glucose, blood $\mathrm{pH}$ and $\mathrm{HCO} 3$ levels in terms of gender $(\mathrm{p}>0.05)$.

\section{Discussion}

Currently T1DM is one of the most common chronic endocrine diseases of the childhood and adolescent period globally, with incidence varying with variables such as age, race, geographical region and season (Forouhi and Wareham 2014). The incidence of T1DM peaks in the 5-7 age group in the early childhood period and again in the pubertal period. The first peak in the early childhood period is thought to be linked to infections, while the second peak in the pubertal period is thought to be linked to stress, growth hormone and gonadal hormones (Shashaj and Sulli 2009; Maahs et al. 2010). A study in Turkey (Demir et al. 2015) reported T1DM was observed in two separate age groups; most commonly in the 6-8 age group followed by the 11-12 age group. In another study by Aydin et al. they reported the most common age groups for T1DM diagnosis were 10-14 years and 14-18 years (Aydin et al. 2016). In our study 17 patients $(42.5 \%)$ were in the 3-9 age group and 25 $(57.5 \%)$ were in the 10-16 age group.

When global studies are examined, a thirty-oneyear study by the Diabetic Study group in Finland reported the incidence of diabetes increased toward younger age groups, there was a clear increase observed in the incidence of diabetes below 5 years while there was no variation in the 10-14 age group (Karvonen et al. 1999). A study by Charkaluk et al. in France reported the incidence of T1DM increased annually by $7.4 \%$, with the annual incidence of diabetic patients under the age of five increasing from $4.2 \%$ to $7.4 \%$ in 10 years (Charkaluk et al.2002). Another study in Germany reported the T1DM incidence in children under five was $6.86 \%$ in 1993 while it rose to $9.68 \%$ in 1995 (Rosenbauer et al. 1999). Though the causes of this situation are not very clear, it is reported that environmental and nutritional factors may be responsible for these changes, not just genetic factors (Silink 2002; Aydin et al. 2016). We consider the adoption of a sedentary lifestyle and increasing place of fast food style eating as the most important causes of the increase in T1DM incidence both in our country and globally.

A study involving 24 centers and 1260 cases by the European Diabetic Study group found the most common symptom in the clinical tableau at diagnosis was polyuria (96\%), with symptom duration longer than 2 weeks in $75 \%$ of cases, while diabetic ketoacidosis clinic varied from 26 to $67 \%$ (LevyMarchal et al.2001). The same study emphasized that the ketoacidosis incidence reduced compared to previous years and the ketoacidosis incidence was highest below the age of 5 . In our study 10 children (25\%) had ketoacidosis on first application to hospital while $3(7.5 \%)$ children were in a coma. Of patients with ketoacidosis, 4 were in the 3-9 age group and 6 were in the 10-16 age group. All of the patients who were in a coma were in the 10-16 age group. Accepted as a marker of glycemic control, HbA1c measurement is one of the important markers of successful treatment. The American Diabetic Association (ADA) recommended that $\mathrm{HbA1c}$ value be held below 7\% after the "Diabetes Control and Complications Trial (DCCT)" study, though many studies reported that reducing HbAlc may cause an increase in hypoglycemia risk especially in small children (Levy-Marchal et al. 2001). According to 2014 ADA data, the target HbA1c level for children and adolescents is recommended as $<7.5 \%$ (Handelsman et al. 2015). In our study the annual mean $\mathrm{HbA1c}$ in male patients was $8.79 \pm 2.28$ while it was $8.14 \pm 2.82$ for female patients, with no statistically significant difference found. Even if total cholesterol does not increase in diabetic patients, linked to LDL cholesterol and triglyceride increase, there is a risk of serious cardiovascular disease linked to the increase in triglyceride amount contained in LDL cholesterol (Wilson 1998). When the results of our study are investigated, the triglyceride levels were statistically significantly 
higher in girls compared to boys. T1DM and accompanying high triglyceride levels increase the risk of development of cardiovascular diseases. Additionally, there was no statistically significant difference observed in fasting plasma glucose $\mathrm{Hb}$, HbA1C, ALT, AST, Na, K, Cl, TK, BUN, creatinine, white cells, hemoglobin, urine $\mathrm{pH}$, urine density, urine glucose, blood $\mathrm{pH}$ and $\mathrm{HCO} 3$ levels. However; the hemoglobin value in group $2\left(14.1 \pm 1.18^{*}\right)$ was found to be statistically significantly high compared to hemoglobin value for the group $1(12.9 \pm 1.68)$ $(\mathrm{p}<0.05)$ and AST value in group $1\left(24.02 \pm 6.57^{*}\right)$ $(\mathrm{p}<0.05)$ was found to be statistically significantly high compared to AST value for the group 2 (18.8 5.43).

In conclusion, it is accepted that globally the incidence of T1DM is increasing and the age of diagnosis is falling. T1DM is a chronic progressive care disease requiring periodic hospital checks in addition to family support. We believe studies relating to awareness of T1DM in Turkey will inform society about diabetes and increase socioeconomic opportunities, proportionally increase the early diagnosis and treatment opportunities for T1DM and cause a significant reduction in the incidence of severe diabetic ketoacidosis and brain edema compared to previous years.

Ethics Committee Approval: Ethics committee approval was received for this study from the approval was obtained from the local Ethical Committee. Permission was granted by the Faculty of Medicine Non-Pharmaceutical Clinical Research Ethics Committee at our university.

Peer-review: Externally peer-reviewed.

Author Contributions: İdea- A. S, E.YE, Design A. S, E. D; Supervision- A. S, E.YE; Funding- A. S; Materials- A. S, E.D.; Data Collection/Data ProcessA. S, E.YE, Analyze or Comment- S.C, Literature Scanning- A. S, E. D; Writer of Paper-A.S.; Critical Review- E.YE, E.D.

Conflict of Interest: No conflict of interest was declared by the authors.

Financial Disclosure: The author declared that this study has received no financial support.

\section{References}

Alberti KG, Zimmet PZ. Definition, diagnosis and classification of diabetes mellitus and its complications. Part 1: diagnosis and classification of diabetes mellitus provisional report of a WHO consultation. Diabetic Medicine, 1998; 15: 53943.

Aydin H, Andiran N, Bulus D, Yagli E. Clinical, Laboratory, Sociocultural and Demographic Features of the Type 1 Diabetes Mellitus Patients. Turkish Journal of Pediatric Disease, 2016; 2: 112119.

Bideci A, Demirel F, Çamurdan O, Cinaz P Evaluation of findings of children with newly diagnosed type 1 diabetes. Çocuk Sağlı̆ 1 ve Hastalıkları Dergisi, 2006; 49: 112-116.

Charkaluk ML, Czernıchow P, Lévy-Marchal C. Incidence data of childhood-onset type I diabetes in France during, 1988-1997: The case for a shift toward younger age at onset. Pediatric Research, 2002; 52: 859-862.

Cruickshanks KJ, LaPorte RE, Dorman JS, et al. The epidemiology of insulin-dependent diabetes mellitus: etiology and prognosis. In: Ahmad PI, Ahmad N (eds). Coping with juvenile diabetes. Springfield, IL: Charles C. Thomas, 1985; 332-57.

Demir F, Günöz H, Saka N, Darendereliler F, Bundak $\mathrm{R}, \mathrm{Baş} \mathrm{F}$, et al. Epidemiologic features of type 1 diabetic patients between 0 and 18 years of age in İstanbul city. Journal of Clinical Research Pediatric Endocrinol, 2015; 7: 49-56.

EURODIAB ACE Study Group. Variation and trends in incidence of childhood diabetes in Europe. Lancet, 2000; 355: 873-6.

Forouhi NG, Wareham NJ. Epidemiology of diabetes. Medicine (Abingdon), 2014; 42: 698-702.

Hamman RF, Bell RA, Dabelea D, et al. The SEARCH for Diabetes in Youth study: rationale, findings and future directions. Diabetes Care, 2014; 37: 3336-3344.

Handelsman Y, Bloomgarden ZT, Grunberger G, Umpierrez G, Zimmerman RS, et al. American Association of Clinical Endocrinologists and American College of Endocrinology Clinical Practice Guidelines for Developing a Diabetes Mellitus Comprehensive Care Plan-2015. Endocr Pract, 2015; 21 (1): 1-87. 


\section{Application Findings of Children with Type 1 Diabetes Diagnosis}

Karvonen M, Pitkaniemi J, Tuomilehto J. The onset age of type 1 diabetes in Finnish children has become younger. The Finnish Childhood Diabetes Registry Group. Diabetes Care, 1999; 22: 106670.

Levy-Marchal C, Patterson CC, Gren A; EURODIAB ACE Study Group. Europe and Dibetes.Geographical variation of presentation at diagnosis of type I diabetes in children: the EURODIAB study. European and Diabetes, 2001; 75-80.

Maahs DM, West NA, Lawrence JM, Mayer-Davis EJ. Epidemiology of type 1 diabetes. Endocrinology Metabolism Clinics of North America, 2010; 39: 481-97.

Onkamo P, Vaananen S, Karvonen M, Tuomilehto J. Worldwide increase in incidence of Type I diabetes - the analysis of the data on published incidence trends. Diabetologia, 1990; 42: 1395403.

Rosenbauer J, Herzig P, von Kries R, Neu A, Giani G. Temporal, seasonal, and geographical incidence patterns of type I diabetes mellitus in children under 5 years of age in Germany. Diabetologia, 1999; 42: 1055-1059.

Shashaj B, Sulli N. Difference in insulin usage patterns with pubertal development in children with type 1 diabetes during transition from multiple daily injections to continuous subcutaneous insulin infusion (CSII) and through the CSII treatment. Diabetes Technology \& Therapeutics, 2009; 11: 767-74.

Silink M. Childhood diabetes: A global perspective. Hormone Research, 2002:57 (suppl 1):15.

Wilson PW. Diabetes mellitus and coronary heart disease. American Journal of Kidney Disease, 1998; 32: 89-100. 